\title{
Sodium Sulfate/Potassium Sulfate/Magnesium Sulfate-based Laxative
}

National Cancer Institute

\section{Source}

National Cancer Institute. Sodium Sulfate/Potassium Sulfate/Magnesium Sulfate-based Laxative. NCI Thesaurus. Code C118453.

An oral preparation containing sodium sulfate, potassium sulfate and magnesium sulfate, with osmotic laxative activity. Upon oral administration of the sodium sulfate/potassium sulfate/magnesium sulfate-based laxative, this osmotic laxative promotes the retention of water in the bowel. This increases the water content of stool, which results in increased gastrointestinal motility and facilitates the evacuation of colonic contents. This results in a complete cleansing of the colon. 